\title{
Онлайн-интервью как новый востребованный жанр журналистики в период самоизоляции
}

\author{
Самойленко Н.С., Кушнир К.И. \\ Воронежский государственный технический университет, \\ Россия, 394006, г. Воронеж, ул. 20-летия октября, 84 \\ E-mail: samoilenkons@gmail.com; ksyu.kushnir.93@mail.ru
}

\begin{abstract}
Аннотация: Описаны основные причины возникновения нового жанра журналистики - онлайнинтервью в современной действительности, проанализированы преимущества онлайн-интервью (возможность проведения интервью без личного присутствия гостя, относительная простота и дешевизна в производстве, оперативность создания контента)и недостатки, включающие в себя необходимость обладания интервьюируемым техническими средствами и навыками, относительно низкое качество видео, получаемого от интервьюируемого, отсутствие живого невербального контакта между собеседниками. Дано определение онлайн-интервью как категории, недостаточно описанной в рамках журналисткой науки. Сделан вывод о том, что данный вид интервью достаточно быстро развивается в период самоизоляции, кроме того, после снятия ограничительных мер данный формат не исчезает, а складывается в самостоятельное направление в рамках журналистского творчества.
\end{abstract}

Ключевые слова: интернет-медиа, новые медиа, самоизоляция, контент, компьютерноопосредованные коммуникации

Для цитирования: Самойленко Н.С., Кушнир К.И. 2021. Онлайн-интервью как новый востребованный жанр журналистики в период самоизоляции. Вопросы журналистики, педагогики, языкознания, 40 (2): 184-190. DOI: 10.52575/2712-7451-2021-40-2-184-190

\section{Online interviews as a new popular genre of journalism during the period of self-isolation}

\author{
Nikita S. Samoilenko, KseniaI.Kushnir \\ VoronezhStateTechnicalUniversity, \\ 84 20-letiya Oktyabrya St, Voronezh, 394006, Russia \\ E-mail: samoilenkons@gmail.com; ksyu.kushnir.93@mail.ru
}

\begin{abstract}
The article describes the main reasons for the emergence of a new genre of journalism - online interviews in modern reality, analyzes the advantages of online interviews (the ability to conduct interviews without the personal presence of a guest, the relative simplicity and cheapness in production, the speed of content creation) and disadvantages, including the need for the interviewee to have technical means and skills, the relatively low quality of video received from the interviewee, the lack of live nonverbal contact between the interlocutors. The definition of online interviews as a category that is not sufficiently described in the framework of journalistic science is given. It is concluded that this type of interview develops quite quickly during the period of self-isolation, in addition, after the removal of restrictive measures, this format does not disappear, but develops into an independent direction within the framework of journalistic creativity.
\end{abstract}

Keywords: digital media, new media, self-isolation, content, Computer-mediatedcommunication 
For citation: Sayenkova-Melnitskaya L.P., 2021. Value-evaluation principles in film criticism. Issues in Journalism, Education, Linguistics, 40 (2): 184-190 (in Russian). DOI: 10.52575/2712-7451-2021-40-2$184-190$

\section{Введение}

Сегодня жанр интервью переживает новую волну популярности в интернет-медиа. Импульс был дан YouTube-каналом журналиста Юрия Дудя, интервью которого набирают большое количество просмотров. Феномен роста популярности жанра интервью в сети интернет уже становился объектом наблюдения научного сообщества [Ковригина, 2008; Жумаева, 2014; Хомутникова и др., 2019; Шестакова, 2019]. Сам Юрий Дудь в ходе интервью с Владимиром Познером противопоставляет свой «новый» жанр (самое популярное интервью на канале набрало более 33 млн просмотров) классическому интервью, которое в телеэфире привлекает аудиторию в несколько миллионов человек ${ }^{1}$. Несмотря на не совсем корректную аналогию, необходимо признать, что данный формат оказался крайне востребованным в условиях трансформации журналистики [Новичихина, Самойленко, 2020] и породил ряд последователей в новых медиа («Осторожно, Собчак», «Нежный редактор», «Пятница с Региной» и т.д.).

К положительным сторонам вышеуказанных интервью можно отнести следующие: традиционную структуру, профессиональную съемку в студии, расположение интервьюеров друг напротив друга и т. д. То есть отличия от традиционных телевизионных интервью относятся не столько к форме, сколько к содержанию. Внимание зрителей зачастую привлекается за счет провокационных вопросов, поднятия табуированных тем, использования девиантной лексики и молодежного сленга.

Мы обратили внимание на то, как жанр интервью видоизменялся в период пандемии. Времена самоизоляции вследствие распространения коронавирусной инфекции привнесли глобальные изменения во многие сферы жизни, в том числе повлияли на массмедиа [Барановская, 2020]. Когда непосредственная встреча с собеседником оказалась невозможной, одним из новых востребованных форматов оказалось онлайн-интервью.

Онлайн-интервью (в некоторых источниках Skype-интервью) активно используется в социологических [Дмитриева, 2018], медицинских [Weinmann et al., 2012] и маркетинговых исследованиях [Александрова, 2019], исторических науках [Вертинова и др., 2019], в сфере управления персоналом [Путилова, 2015] (HR) как метод получения информации [Salmons, 2014]. (Отметим, что сего дня использование наименования Skype-интервью неправомерно, так как в последние годы, а особенно в период самоизоляции, появились другие крупные сервисы, такие как Zoom ${ }^{2}$ и WhatsApp ${ }^{3}$, позволяющие проводить онлайнинтервью.) Но сама категория «онлайн-интервью» оказывается недостаточно описанной в рамках журналисткой науки.

Данный вид интервью получил быстрое развитие в период самоизоляции, и нами была выдвинута рабочая гипотеза, что после снятия ограничительных мер, данный формат не исчезнет. Журналисты смогут избирать данный вид работы в тех случаях, когда посчитают это необходимым: для организации онлайн-встреч с собеседниками, находящимися на значительном удалении от студии, в труднодоступных местах, когда необходимо в сжатые сроки организовать интервью.

\footnotetext{
${ }^{1} \mathrm{https}: / /$ www.youtube.com/watch?v=wg-TMymYSwE (дата обращения: 09.02.2021).

${ }^{2} \mathrm{https} / / /$ www.bbc.com/news/business-52884782 (accessed: 09.02.2021).

${ }^{3} \mathrm{https}: / /$ techcrunch.com/2020/03/26/report-whatsapp-has-seen-a-40-increase-in-usage-due-tocovid-19-pandemic/ (accessed: 09.02.2021).
} 
На первом этапе исследования мы провели контент-анализ СМИ и новых медиа в период действия самых значительных ограничений, связанных с распространением коронавирусной инфекции (апрель - май 2020 года), с целью выявить частотность внедрения онлайн-интервью в телевизионные и интернет-эфиры. На втором этапе мы повторили исследование в период, когда большая часть ограничений была снята (январь - февраль 2021 года). В рамках как первого, так и второго этапов отдельно рассматривались формы онлайн-интервью, творческие приемы и технологические особенности, использованные при их производстве.

\section{Результаты и их обсуждение}

Мария Лукина выделяет такую форму организации интервью, как «интервью с помощью разных служб Интернета». «Электронная почта, форум, чат и т. д. - возможные пути для сбора информации и проведения интервью. Если же нужно получить официальный комментарий, переписки в чате будет недостаточно. Тогда можно поговорить с интервьюируемым по видеосвязи» [Лукина, 2003]. Онлайн-интервью относится к так называемым Computer-mediated communication (CMC) [Chin, 2016]. В рамках исследования мы, вслед за другими учеными [Воевудская, Шурлина, 2019], определяем такой вид взаимодействия как «компьютерно-опосредованная коммуникация». В теории компьютерноопосредованных коммуникаций (CMC) такие виды коммуникации разделяют на асинхронные и синхронные [Chin, 2016]. Именно последние - синхронные онлайн-интервью оказываются наиболее близкими к традиционным интервью и позволяют журналисту в режиме реального времени получать информацию от собеседника, а аудитории - наблюдать за коммуникационным актом. При этом онлайн-интервью, как и телевизионные, разделяют на транслируемые в прямом эфире и в записи (часто в интернет-среде для обозначения прямого эфира употребляется термин «стрим» от англ. Stream - поток [Арбузов и др., 2020]).

По причине отсутствия закрепленного термина «онлайн-интервью» в рамках журналисткой науки, мы предлагаем свое определение.

Онлайн-интервью - это жанр публиичистики, беседа интервьюера с одним или несколькими лицами, компьютерно-опосредованная коммуникаџия, позволяющая получать журналисту актуальную информацию в режиме реального времени и транслировать ее как в прямом эфире, так и в записи.

На первом этапе исследования мы рассмотрели процесс актуализацииданного жанра в период самоизоляции. Так, в период действия самых строгих ограничительных мер эфир телеканала «РБК» от 31 мая 2020 годаза сутки транслировал 30 онлайн-интервью (общей продолжительностью 25 минут), что составило 52,08\% суточного телеэфира ${ }^{1}$.

Не остались в стороне и федеральные СМИ. «Первый канал» также инкорпорировал онлайн-интервью в свой эфир. На федеральном телеканале конвергентная форма встречается чаще в развлекательных программах, таких как «Доброе утро» или «Вечерний Ургант» (серия онлайн-интервью под названием «Встречи на безопасном расстоянии»).

Нельзя не отметить, что в интернет-среде онлайн-интервью также активно заполнили эфир. Одним из популярных спикеров стал экономист Сергей Гуриев. Дистанционный формат позволил ему в сжатые сроки дать несколько интервью для самых разных источников, начиная с малоизвестных YouTube-каналов и заканчивая такими СМИ, как «Эхо Москвы», «Дождь»².

На втором этапе исследования мы провели контент-анализ телевизионных и интернет-эфиров указанных выше СМИ после снятия большей части ограничительных мер в январе - феврале 2021 года.

\footnotetext{
${ }^{1}$ https://tv.rbc.ru/archive/ekskluziv/5ed0cf132ae5966cfdb9a418 (дата обращения: 09.02.2021).

${ }^{2} \mathrm{https}: / / \mathrm{www}$. youtube.com/watch?v=nsN6AiOAdII\&t=686s (дата обращения: 09.02.2021).
} 
Так, возвращаясь к телеканалу РБК, мы обнаружили, что онлайн-интервью на 1 февраля 2021 года составляют 15,3 \% от общего суточного эфира телеканала. Однако, в рамках рубрики «эксклюзивные интервью» процент онлайн-интервью достигает 50 \%. Так же короткие онлайн-интервью оказываются встроены во многие другие телепрограммы, такие как «Главные новости», «Что Это Значит» и другие.

Многие спикеры, которые активно участвовали в онлайн-интервью весной 2020 года, продолжили данную деятельность и в начале 2021 года, особенно на таких интернетплощадках, как YouTube. Здесь необходимо пояснить, что, несмотря на снятия большей части ограничительных мер по противодействию короновирусной инфекции в Российской Федерации к февралю 2021 года, международные перелеты и трансграничное сообщение остаются закрытыми по многим направлениям. Соответственно, онлайн-интервью выступает единственно возможным способом провести эфир с собеседниками, которые находятся в других странах.

Рассмотрение практики функционирования онлайн-интервью позволило нам выделить ряд преимуществ и недостатков.

К преимуществам онлайн-интервью относятся:

- возможность проведения интервью без личного присутствия гостя в студии и на любом расстоянии;

- относительная простота и дешевизна в производстве;

- оперативность создания контента.

Недостатки онлайн-интервью:

- интервьюируемый должен обладать необходимыми техническими средствами и навыками;

- на данном этапе качество аудиовизуального сигнала, получаемого от интервьюируемого, недостаточно высоко по отношению к современным телевизионным стандартам;

- отсутствует живой невербальный контакт между собеседниками.

При этом необходимо отметить, что на данный момент не существует единого подхода к форме проведения такого интервью. На первом этапе весной 2020 года мы выделили следующие формы проведения онлайн-интервью: в рамках эксклюзивных онлайнинтервью в эфире телеканала «РБК» попеременно выдаются планы с компьютера интервьюера, интервьюируемого и планы, снятые на профессиональную камеру, показывающие работу журналиста в студии. Однако в утреннем шоу «Стартап» на том же телеканале «РБК» видео с интервьюируемым выдается на четверти экрана, а оставшуюся часть экрана занимает инфографика. Для того, чтобы скрыть недостатки качества записи интервьюируемого, видео выводится в черно-белом цветовом решении. Иван Ургант иронизирует над ситуацией и общается с телевизором, на который транслируется видео с интервьюируемым в то время, как телевизор находится на руках у его ассистента. Канал «RTVI» проводит онлайн-интервью с участием двух интервьюеров, сидящих в кресле напротив телеэкрана с изображением собеседника. Журналист Дмитрий Гордон в рамках интернетэфира выдает на экран два изображения одновременно- интервьюера и его и собеседника.

В 2021 году мы наблюдаем некоторые изменения. Так, телеканалом РБК была подготовлена специальная студия, в которой интервьюер находится в кресле перед экраном, развернутым в вертикальной ориентации, которая в большей степени соответствует пропорциям находящегося «по ту сторону» интервьюируемого. Таким образом, сама форма онлайн-интервью рождается на наших глазах и оставляет значительное пространство для творчества и экспериментов. 


\section{Заключение}

Подводя итоги, хотелось бы отметить, что онлайн-интервью как жанр журналистского творчества получило быстрое развитие в период самоизоляции. Нами была выдвинута рабочая гипотеза, что после снятия ограничительных мер, данный формат не исчезнет. Второй этап исследования показал, что в процентном соотношении после снятия ограничительных мер количество онлайн-интервью уменьшилось по сравнению с периодом действия самых жестких ограничительных мер, однако во многих случаях онлайнинтервью стали неотъемлемой частью телевизионных и интернет-эфиров.

Сегодня журналисты могут избирать данный вид работы в тех случаях, когда считают это необходимым: для организации онлайн-встреч с собеседниками, находящимися на значительном удалении от студии, в труднодоступных местах, когда необходимо в сжатые сроки организовать интервью.

\section{Список литературы}

1. Александрова И.Ю. 2019. Методология маркетингового исследования интернетпользователей. E-Management, 2 (1): 7-18. DOI: https://doi.org/10.26425/2658-3445-2019-1-7-18.

2. Арбузов С.С., Грибан О.Н., Грибан И.В. 2020. Применение технологии стрим-обучения в педагогическом вузе: подходы к оценке эффективности. Педагогическое образование в России, 1: 58-64.

3. Барановская П.А. 2020. Влияние пандемии коронавируса на деятельность средств массовой информации (на примере интернет-проекта хакасии "репаблик"). Вестник ХГУ им. Н.Ф. Катанова, 2 (32): 57-63.

4. Вертинова А.А., Бородина Д.М., Воронова К.Н. 2019. Диджитализация сферы управления персоналом. Карельский научный журнал, (3 (28)), т. 8: 81-83.

5. Воевудская О.М., Шурлина О.В. 2019. Компьютерно-опосредованная коммуникация: характерные черты и специфические особенности. ART LOGOS, 1 (6): 98-110.

6. Дмитриева О.А. 2018. Скайп-интервью в качественных исследованиях. Обзор. Мониторинг, 1 (143): 107-116.

7. Жумаева О.А. 2014. Анализ интернет-интервью через призму фактора адресата. Вестник Челябинского государственного университета, 10 (339): 56-63.

8. Ковригина Е.А. 2008. Дискурсивные стратегии интервьюера (на материале американского интернет-интервью). Вестник Бурятского государственного университета. Язык. Литература. Культура, 11: 85-90.

9. Лукина М.М. 2003. Технология интервью. М., Аспект Пресс, 191 с.

10.Новичихина М.Е., Самойленко Н. С. 2020. Новые медиа и новые функции медиатекста: к вопросу о трансформации современной журналистики. Верхневолжский филологический вестник, 2: 92-98.

11.Путилова Е.Г. 2015. Эволюция биографического метода: особенности проведения online-интервью. Ученые записки Орловского государственного университета. Серия: Гуманитарные и социальные науки, 2 (65): 22-26.

12.Хомутникова Е.А., Джалилов Р.А., Иноятова К.Ш. 2019. Технологии создания интервью для молодежи в интернет-СМИ. Медиасреда, 2: 45-49.

13.Шестакова П.С. 2019. Применение жанра интервью в интернет-пространстве. Медиасреда, 1: 98-102.

14.Chin L. 2016. Advantages and Disadvantages of Computer Mediated Communication in the Context of Unimas Students fnd Staff. New technocomm. Available at: https://newtechnocomm.wordpress.com/2016/03/05/advantages-and-disadvantages-of-computer-mediated -communication-in-the-context-of-unimas-students-and-staff/ (accessed: 09.02.2021).

15.Mc Quail D. 2005. McQuail's Mass Communication Theory. London, SAGE Publications, $534 \mathrm{p}$. 
16.Salmons J. 2014. Qualitative Online Interviews: Strategies, Design, and Skills. SAGE Publications, $320 \mathrm{p}$.

17.Weinmann T., Thomas S., Brilmayer S., Heinrich S., Radon K. 2012. Testing Skype as an interview method in epidemiologic research: response and feasibility. International Journal of Public Health. 6: 959-961.

\section{References}

1. Aleksandrova I.Yu. 2019. Metodologiya marketingovogo issledovaniya internet-pol'zovateley [Methodology of marketing research of Internet users]. E-Management, 2(1): 7-18. DOI: https://doi.org/10.26425/2658-3445-2019-1-7-18.

2. Arbuzov S.S., Griban O.N., Griban I.V. 2020. Primenenie tekhnologii strim-obucheniya v pedagogicheskom vuze: podkhody k otsenke effektivnosti [Application of stream-teaching technology in a pedagogical university: approaches to assessing effectiveness]. Pedagogical Education in Russia, 1: 58-64.

3. Baranovskaya P.A. 2020. Vliyanie pandemii koronavirusa na deyatel'nost' sredstv massovoy informatsii (na primere internet-proekta khakasii "repablik") [The impact of the coronavirus pandemic on the activities of the media (on the example of the Internet project of Khakassia "Republik")]. Vestnik Khakasskogo gosudarstvennogo universiteta im. N.F. Katanova, 2 (32): 57-63.

4. Vertinova A.A., Borodina D.M., Voronova K.N. 2019. Didzhitalizatsiya sfery upravleniya personalom [Digitalization of the sphere of personnel management]. Karelian Scientific Journal, (3 (28)), vol. 8: 81-83.

5. Voevudskaya O.M., Shurlina O.V. 2019. Komp'yuterno-oposredovannaya kommunikatsiya: kharakternye cherty i spetsificheskie osobennosti [Computer-Mediated Communication: Characteristics and Specific Features]. ART LOGOS, 1 (6): 98-110.

6. Dmitrieva O.A. 2018. Skayp-interv'yu v kachestvennykh issledovaniyakh. Obzor [Skype interviews in qualitative research. Overview]. Monitoring, 1 (143): 107-116.

7. Zhumaeva O.A. 2014. Analiz internet-interv'yu cherez prizmu faktora adresata [Analysis of Internet interviews through the prism of the addressee factor]. Bulletin of Chelyabinsk State University, 10 (339): 56-63.

8. Kovrigina E.A. 2008. Diskursivnye strategii interv'yuera (na materiale amerikanskogo internet-interv'yu) [Interviewer's Discourse Strategies (Based on American Internet Interviews)]. Vestnik of Buryat State University. Language. Literature. Culture, 11: 85-90.

9. Lukina M.M. 2003. Tekhnologiya interv'yu [Interview Technology]. M., Publ. Aspekt Press, $191 \mathrm{p}$.

10.Novichihina M.E., Samojlenko N. S. 2020. Novye media i novye funkcii mediateksta: k voprosu o transformacii sovremennoj zhurnalistiki. Verhnevolzhskij filologicheskij vestnik, 2: 92-98.

11.Putilova E.G. 2015. Evolyutsiya biograficheskogo metoda: osobennosti provedeniya onlineinterv'yu. Scientifi c Notes of Orel State University. Series Humanities and social sciences, 2 (65): 22-26.

12. Khomutnikova E.A., Dzhalilov R.A., Inoyatova K.Sh. 2019. Tekhnologii sozdaniya interv'yu dlya molodezhi $\mathrm{v}$ internet-SMI [Technologies for creating interviews for young people in online media]. Mediasreda, 2: 45-49.

13. Shestakova P.S. 2019. Primenenie zhanra interv'yu v internet-prostranstve [Application of the interview genre in the Internet space]. Mediasreda, 1: 98-102.

14. Chin L. 2016. Advantages and Disadvantages of Computer Mediated Communication in the Context of Unimas Students fnd Staff. Newtechnocomm. Available at: https://newtechnocomm. wordpress.com/2016/03/05/advantages-and-disadvantages-of-computer-mediated-communication-in-thecontext-of-unimas-students-and-staff/ (accessed: 09.02.2021).

15. McQuail D. 2005. McQuail's Mass Communication Theory. 5London, SAGE Publications, $534 \mathrm{p}$.

16. Salmons, J. 2014. Qualitative Online Interviews: Strategies, Design, and Skills. SAGE Publications, $320 \mathrm{p}$.

17. Weinmann T., Thomas S., Brilmayer S., Heinrich S., Radon K. 2012. Testing Skype as an interview method in epidemiologic research: response and feasibility. International Journal of Public Health. 6: 959-961. 


\section{ИНФОРМАЦИЯ ОБ АВТОРАХ}

Самойленко Никита Сергеевич, кандидат филологических наук, старший преподаватель кафедры русского языка и межкультурной коммуникации Воронежского государственного технического университета, г. Воронеж, Россия

Кушнир Ксения Игоревна, ассистент кафедры русского языка и межкультурной коммуникации Воронежского государственного технического университета, г.Воронеж, Россия

\section{INFORMATION ABOUT THE AUTHORS}

Nikita S. Samoilenko, Candidate of philological sciences, Senior Lecturer of the Chair of Russian Language and Intercultural Communication, Voronezh State Technical University, Voronezh, Russia

Ksenia I. Kushnir, Assistant of the Chair of Russian Language and Intercultural Communication, Voronezh State Technical University, Voronezh, Russia 